\title{
Clinical efficacy of dupilumab in the treatment of severe chronic rhinosinusitis
}

Matteo Trimarchi ${ }^{1}$, Pietro Indelicato ${ }^{2}$, Alessandro Vinciguerra $^{2}$, and Mario Bussi ${ }^{2}$

${ }^{1}$ Affiliation not available

${ }^{2}$ San Raffaele Hospital

December 2, 2020

\begin{abstract}
Chronic rhinosinusitis with nasal polyps is a type 2-mediated inflammatory disease associated with significant burden due to symptoms and high recurrence rate after surgery. Dupilumab, a monoclonal antibody against the interleukin- 4 receptor subunit $\alpha$, has demonstrated good clinical efficacy and acceptable safety in phase II and phase III trials.
\end{abstract}

\section{Hosted file}

Manuscript.pdf available at https://authorea.com/users/380664/articles/496563-clinicalefficacy-of-dupilumab-in-the-treatment-of-severe-chronic-rhinosinusitis

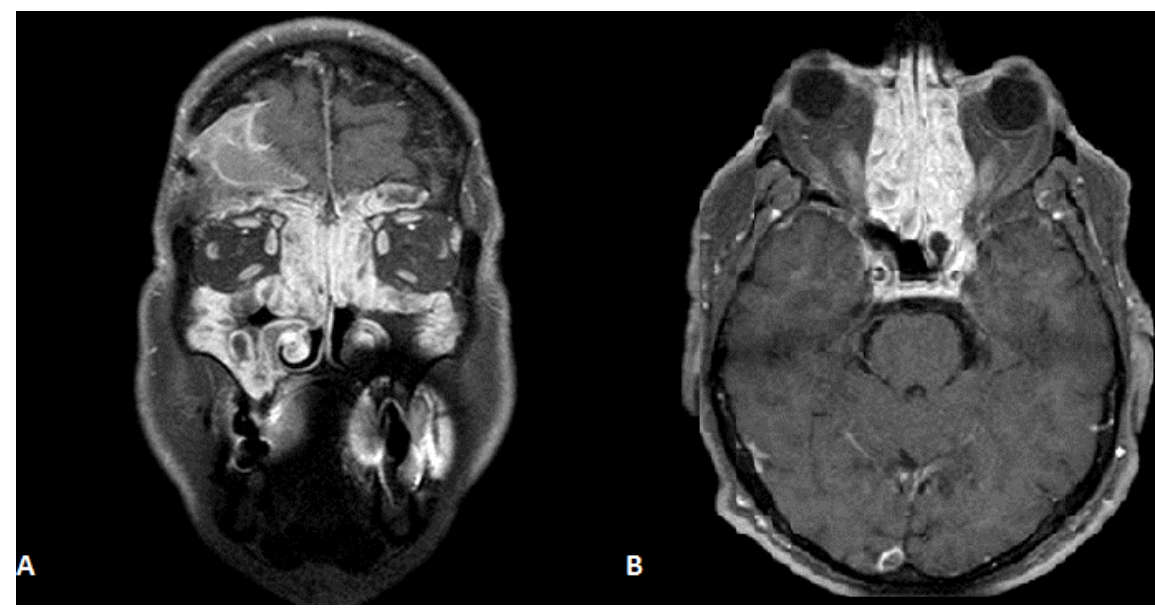




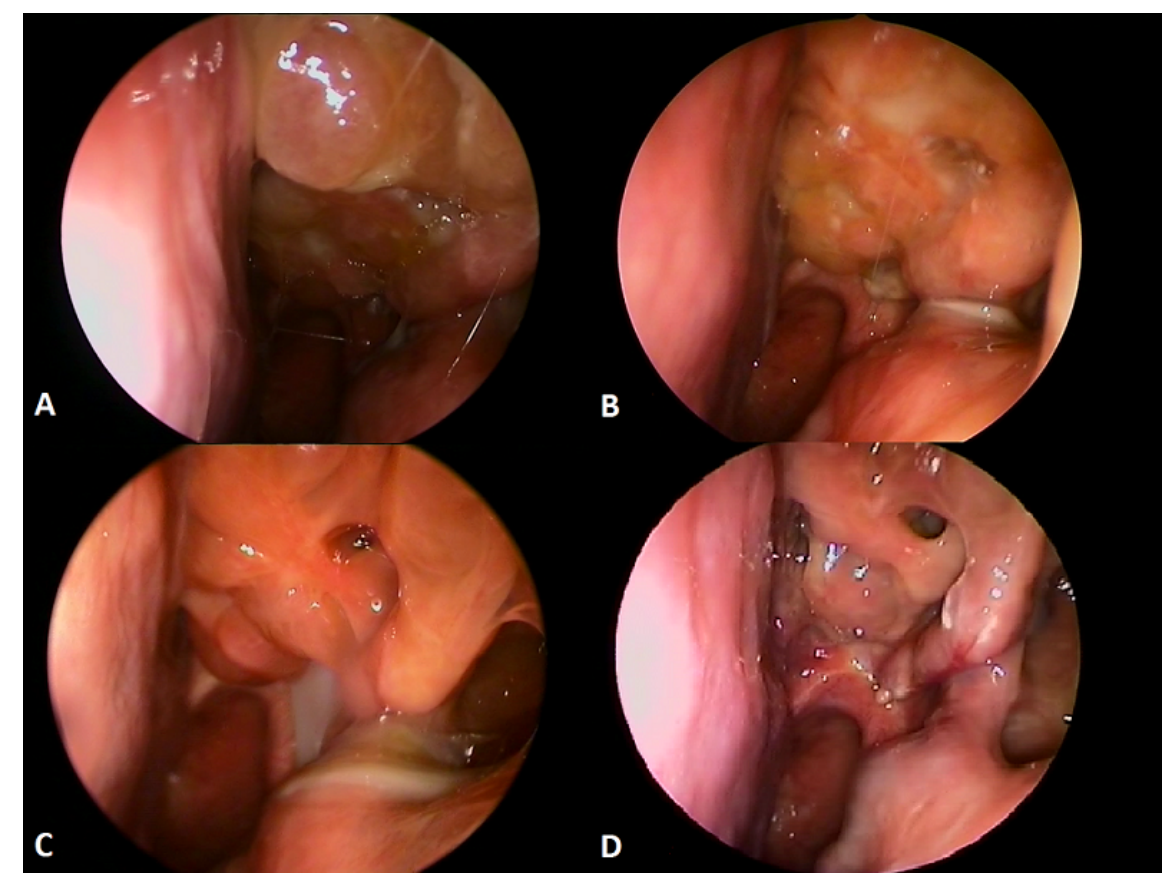



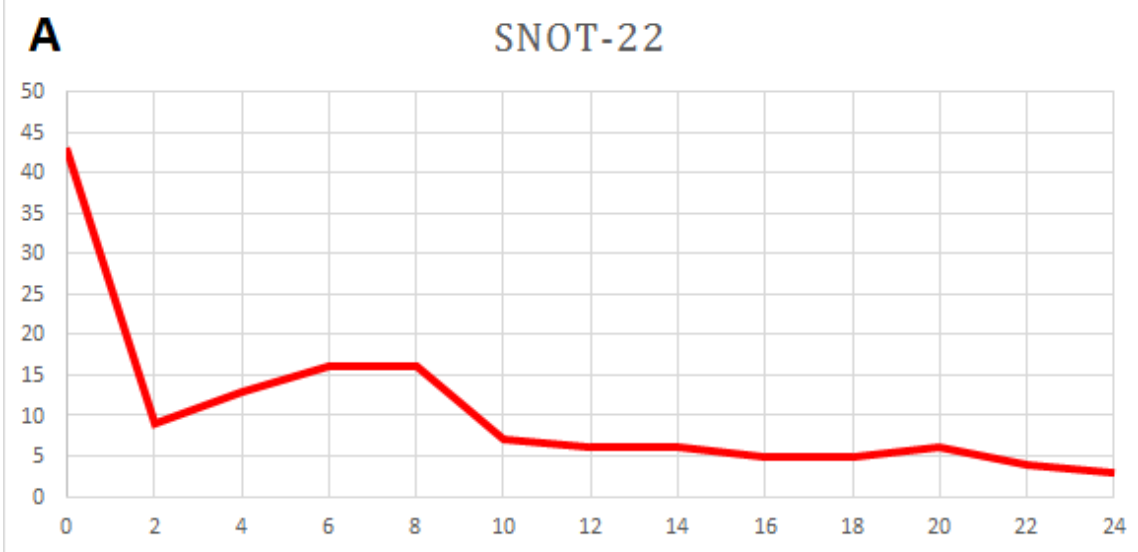

\section{B}

UPSIT-40

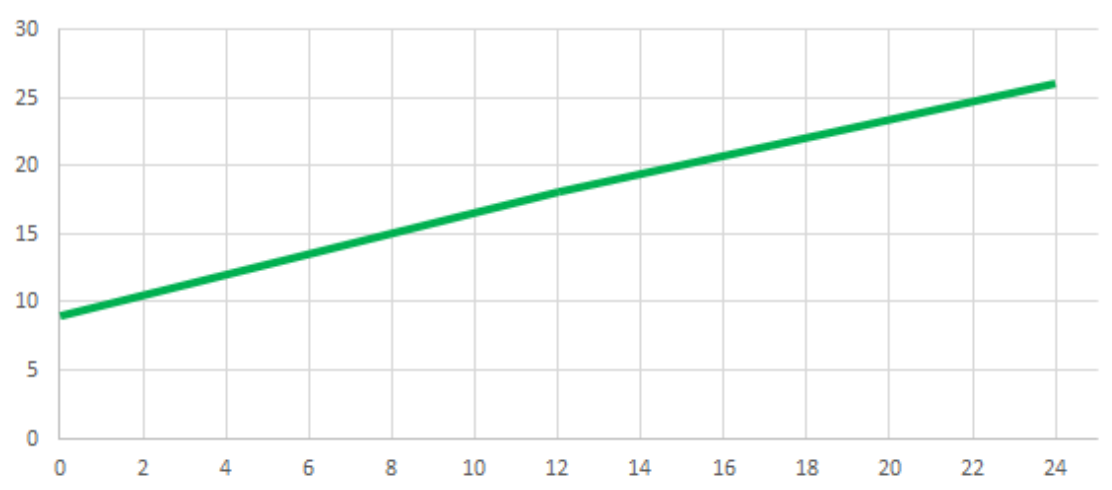

